disappeared and the breath sounds were diminished over both lungs, with the exception of the lower right lobe and the upper left lobe, where the breathing was broncho-vesicular, with moist râles on inspiration, and here and there an area of increased vocal resonance. The percussion note was slightly dulled over the left apex, where "tidal percussion" revealed diminished expansion. He was given benzoin inhalations and 6 grains of quinine thrice a day, in the hope that there might be an element of malaria in his condition. Daring this week he complained of malaria in his condition. During this week he com

of profase sweats at night and diarrhoea commenced.
During the second week he complained of sharp pain in the right side, where friction was frequent, and the breath sounds underwent further modification. The breathing was harsh and broncho-vesicular all over the chest, with copious musical rhonchi both on inspiration and expiration. Here and there over all lobes were patches, showing bronchial breathing and increased vocal resonance, whilo the "tidal percussion" showed no expansion at either apex or at the bases behind, where dry inspiratory clicks during inspiration were heard. The sputum contained tubercle bacilli and elastic tissue, but was not copious. After the initial rise, the temperatqre remained continuously high, between $101^{\circ}$ and $102^{\circ} \mathrm{F}$., with an absence of remissions. The pulse, following the temperature, showed no remissions, and during the first two weeks averaged 80 , but during the third week rose to an average of 94. Respirations ranged between 22 and 24 .

It is obvious that in this case we were dealing with the comparatively rare condition in the adult of acute tuberculous bronchopneumonia. Prior to the operation the patient had neither cough nor sputum, while a careful examination revealed no abnormality of the chest. Further, the patient denied the slightest sign of chest disease prior to the present illness, and the family history was good. At the same time, it is probable that he bad a latent focus of infection, which only required a lowered resistance to break out into this grave form of phthisis. When we recall the fact that 90 per cent. of normal

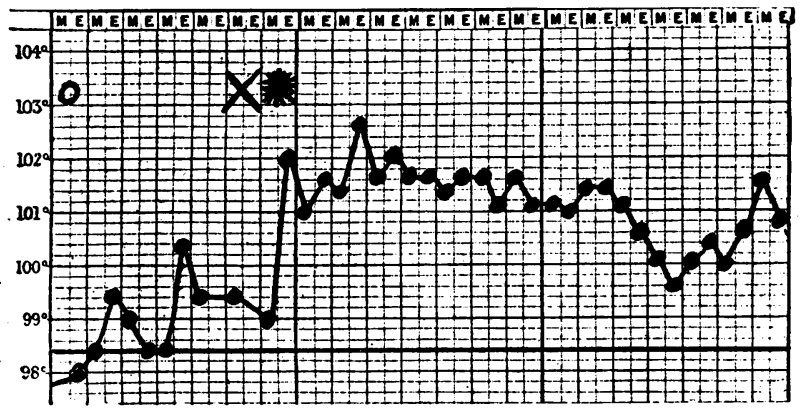

u, Oparation: $\mathrm{x}$, chcst examined, nil ; $*$ onset of acute tuberculous bronchopneumonia.

persons have had, at one time or another, some focus of infection in the lungs, the etiology of the case is not obscure. In spite of the long period of disturbed nutrition consequent on the intestinal lesion, this patient presented sufficient resistance to hold the disease in check until some condition so weakened the pulmonary resistance that in $t w 0$ weeks the two lungs were infected in every lobe.

Since the operation of gastro enterostomy has come to be one of the most frequent in abdominal surgery, it has been generally recognized, especially on the Continent, that the danger of the operation itself is nothing compared to the risk of post-operative pulmonary infection, which usually takes the form of bronchopneumonia. In view of the bovine and ingestion theory of tubercu. lous infection, there is no doubt that the long period of intestinal disease would predispose to the entrance of the tubercle bacillus into the system, but any suspicion of the duodenal ulcer being tuberculous was negatived by the clinical history of the case; the appearance of the ulcer at operation, and a negative result in examining the faeces for tubercle bacilli. The patient died in six months from this acute form of pulmonary tuberculosis. Relief from gastric symptoms was complete.

The incidence of phthisis supervening on chronic gastric or duodenal ulcer is given by different authorities at 20 to 27 per cent. of the complications of the gastric or intestinal lesion; and, in view of the fact experimentally proved that a lesion of the intestinal tract favours the absorption of tubercle bacilli into the lymph. atic and circulatory systems, by either of which routes they may reach the lung, there is a clear indication for the earlier resort to surgical measures in cases of chronic ulcers which are not benefited by medical treatment.

\section{A TYPHOID CARRIER.}

BY

J. R. HUTCHINSON, M.B., D.P.H.,

ASSISTANT TO THE MEDICAL OFFICER OF HEALTH, MANCHESTER.

The circumstances of this case are briefly as follows:

J. H. W., aged 36, commenced with enteric fever on or about September 24th, 1908. Widal's test was positive on October 19th 1908. This patient had been living at the house in which he then was for four days. Prior to this he had lodged for some months at the house of a Mrs. W., a widow, who gets her living by taking in lodgers. She does all her own housework, and commonly has two or three lodgers.

At the same house in which J. H. W. was presumably infected, three previous cases (II, III, and IV) of enteric fever had occurred amongst Mrs. W.'s lodgers.

CASE II (130, 1907).

J. W. E., aged 19, commenced to be ill on September 7th, 1907. On September 28th he was removed to the fever hospital. His blood gave a positive reaction. He recovered.

\section{CASE III $(224,1906)$}

A. A., aged 28, commenced to be ill on September 4th, 1906 . His blool gave a positive reaction. Death occurred on October 16th, 1906.

CASE IV $(135,1906)$.

A. W., aged 28, commenced to be ill on May 2nd, 1906. His blood gave a positive reaction. Death took place on June 14th, 1906.

All these four cases were infected between May, 1906, and September, 1908, at the one house kept by Mrs. W. during this period. Three further cases were traced to two other houses at which Mrs. W. had previously taken in lodgers.

CASE v $(174,1905)$.

H. R., aged 19. Onset of disease, May 20th, 1905. Blood reaction positive. There is just a chance that this patient was
infected outside Manchester, but this is unlikely. He had lodged at this house for three months.

CASE vi (118, 1905).

H. P., aged 25. Onset, April 8th, 1905. Blood reaction posi tive. A daughter of $H$. P.'s too had a prolonged febrile illness about this time; the details of this illness are not forthcoming; a blood specimen could not be obtained. Both father and daughter were lodgers with Mrs. W.

\section{Case VII (388, 1898).}

W. D., aged 23. Onset, October 4th, 1898. Removed to the fever hospital, and died November lst, 1898. For six weeks prior to October 4th W. D. had lodged with Mrs. W:

The only factor common to all these cases is the presence of Mrs. W. No history of contact with known enteric fever cases, or of consumption of food likely to be infected, was obtainable in any of these cases.

Mrs. W.'s medical history is as follows: Up to 1893, when she was about 54 years old, she enjoyed good health, and never had occasion to see a medical man. In this year she had an attack of "influenza and pneumonia," for which she was treated in a union hospital. She remembers little about this illness except that she had severe headaches and pains in the back, and was delirious. She was ill for five weeks, and was fed entirely on fluid foods. Since this illness she has suffered from periodic attacks of abdominal pain and vomiting. These attacks did not follow immediately on the illness of 1893 ; there was an interval of five years during which her health was good. A specimen of blood obtained in November, 1907, gave a negative reaction.

Five of the seven cases recorded above are also recorded in the annual report of the medical officer of health for Manchester for 1907. The occurrence of a sixth case in September, 1908, caused further search to be made, when a seventh was discovered so far back as 1898.

No cases can be found as having occurred at the house of Mrs. W. prior to 1898. Possibly some may have been overlooked. It was not until 1898 that Mrs. $\mathrm{W}$. began to suffer from attacks of abdominal pain and vomiting after her five years of good health. The year she began to be ill was marked by the appearance of the first known. case of enteric fever amongst her lodgers. There is no. doubt that she was ill before her lodger.

It is curious that no further cases should come to light between 1898 and 1905; certainly none were notified during this period. It is a well.known fact that in "carrier." cases the bacilli are excreted in the stools and urine in batches with bacillus-free intervals. Many such batches must have been shed from time to time during these years. In October, 1908, Mrs. W. was examined by 
the practitioner who usually attended her; he was unable to detect any abnormal physical signs-the liver was not enlarged, the gall bladder could not be felt, there was no evidence of gall stones. He had had the patient under treatment on and off for years for "indigestion and chronic constipation." So far as he knew, she had never been jaundiced.

On November 4th, 1908, Mrs. W.'s blood gave a positive reaction in thirty minutes. The same evening she was given, in accordance with Professor Delépine's method, a dose of sulphate of soda, and next morning specimens of her faeces and urine were obtained. Both contained typhoid bacilli. A month later (December 3rd) further specimens were obtained without the administration of a cathartic; on this occasion the bacilli were found by Professor Delépine in the faeces only; the urine was sterile. Attempts to obtain further specimens of blood from Mrs. W. were unsuccessful.

It seems highly probable that the influenze and nneumonia of 1893 was in reality enteric fever. It is remarkable that she is not known to have infected any one prior to 1898 , particularly so as she was engaged in general housework, including the preparation of food, etc., for her lodgers. Certainly her attacks of abdominal pain, etc., do not seem to have troubled her prior to the middle of 1898 .

She cannot, when her serum gave a positive reaction in Norember, 1908, have been infected by J. H. W., the last case to occur in her house, as not only did her excretions contain typhoid bacilli at that time, but they were present in her faeces on December 3rd, six weeks after J. H. W. had been removed to hospital.

The negative reaction obtained in November, 1907, is not of great importance, for, as Doerr ${ }^{1}$ showed in 1905, the persistence of typhoid bacilli in the bile is unable to preserve the agglutinating properties of the blood.

It has been pointed out also by German observers that this not infrequently occurs. Forster and Kayser ${ }^{2}$ suggest that the attacks of abdominal pain, vomiting, etc., which occur from time to time are due to local inflammatory changes in the gall bladder set up by the contained bacilli, and that with each attack more agglutinating substances derelop in the blood stream. Widal's reaction, then, would prob3bly be obtained with a specimen of blood taken soon after one of the periodic attacks of abdominal pain, etc., but with the lapse of time, and without the assistance of another attack, the serum would lose its agglutinating properties. Mrs. W. has had "stomach attecks" at intervals of a "fow days" for upwards of ten Jears.

None of the patients returned to lodge again at Mrs. W.'s after recovery ; there is no question, therefore, of any one of them being responsible for any subsequent case.

It is interesting to find that the last 6 of the 7 cases had been living at the house of Mrs. W. for four, three, two, three, three-quarters, and one and a half months respectively bofore they became infected. No record of the length of time that Case I had been here prior to infection was made. This calls to mind Kayser's famous case of the Strassburg baker. ${ }^{3}$

There appears to be some element of periodicity in the cases infected ; this has been previously noticed by Davies and Walker Hall.

For permission to publish this case I am indebted to Dr. Niven. REFERENCES.
1 Doerr, Centrulbl.f. Bakt., 1905, v, 392 Forster and Kayser, Münch.
med. Woch., 1905. No. 31. 3 Kayser, Arb rit. aus dem Kais. Gesund., 1906, B. 24. ${ }^{2}$ Disies and Walker Hall, BRITISH Medical JodRNAI October 17 th, 1908 .

THE E.M.I. (oeuvre d'Enseignement Médical Complémentaire), which is under the patronage of the French Government, has this year chosen Belgium and Holland as the scenes of its tour of medical study. The tour will last from August 1st to the 20th. The party will start from Luille, returning by way of Luxemburg and Alsace, and separating at Vittel. It will visit Ostend, Middelkerke, Blankenberg. Bruges, Ghent, Brussels, Louvain, Antwerp, Rotterdam, The Hague, Leyden, Amsterdam, the Isle of Marken, Utrecht, Liége, Spa, Bourgoumont, Luxemburg, Strassburg, Munster, Schlucht, and Gerardmer. The assosiation issues a journal entitled L'Enseignement II jedico-Mutuel International (published at 12, rue Francois Millet, Paris XVIèmo) in whinh detailed information is given.

\section{SYPHILITIC LEUCODERMA IN A MALE.}

BY

Staff Surgeon KenNeTH H. JONES, M.B. ROYAL NAVY.

The following caso is of interest, both because it occurred in a male-an event of considerable rarity-and because of the large area affected.

W. R., aged 21 , a newly entered stoker recruit, was on April 20th, 1909, picked out of about 200 men and boys, all stripped to the waist, and awaiting their examination by a medical officer as to personal cleanliness He stated that previously to enlistment he was employed as a fireman at previously to enlistment he was employed as a fireman at
works in the North of England. He admitted having contracted syphilis about three yeurs before, and the scar of the chancre was very obvious on the glans penis, near the meatug. According to his own account, he had saffered very little Irom secondary symptoms, and had had no regular or continuous treatment with mercury. With this exception he had always enjoyed very good health.

He was of blonde Saxon type, with very fair hair and blue ejes, well nourished and muscular. The whole of the trunk, both anteriorly and posteriorly, to about the level of the umbilicus, as well as the upper extremities as far down as the insertions of the deltoid muscles, was affected. The skin was to some extent pigmented, and in certain regions very dark indeed; whilst over the whole there appesred whitish rounded or oval mottlings or dapplings, most obvious where the surrounding cuticle was most deeply coloured. The pigmentation was most marked in the region over the outer two-thirds of the clavicles, and more so immediataly above than just below them in the middle line, over the inner thirds of these bones and over the upper edge of the sternum, it paled very markedly. The skin over the outer two-thirds of the clavicles, and for about 1 to 1 in in. above, was a deep brown, like that of a lightly. coloured Indian; that of the rest of the neck was normal. After these areas, the darkest parts were those over the top of the shoulders and over the deltoid muscles, pigmentation being very marked as far down as the insertions of the latter. The very dark coloration did not continue round the back of the neck in the form of a collar. In all the above areas the dappling was exceedingly obvious, the whitish patches being well defined and their edges sharply cut. Over the rest of the trunk, ventrally and dorsall 7 , the condition was well marked but the pigmentation was less, the colour being of a light yellowish-brown; the dapplings in conseguence were less yellowish-brown; the dapplings in consequence were less
obvious, and showed less tendency to be sharply circumscribed. About the level of the umbilicus was a well-marked impression from the wearing of a tight belt, and below this the peculiar skin coloration was abeent. The pale areas or dapplings varied from $\frac{1}{2}$ to $\frac{3}{4}$ in. in dismeter, and tended to become smaller as well as less well defined on the chest, sides, hack, and abdomen than in the clavicular regions and over the deltoids.

After an interval of six months, when an opportunity again occurred of making observations, the condition was, on the whole, slightly less evident than before, bat was still most marked just over the clavicles and deltoid muscles; the whitish dapplings showed a tendency to be less circumscribed, and the pigmented areas to decrease, both in extent and depth of coloration. The dapplings showed a tendency to run into one another, especially on the abdomen. In the region of the nipples and over the scapulae all pigmentation had disappeared, together with the characteristic whitish areas (dapplings). The mark of the belt had gone, but no pig mentation occurred below its former situation. Posteriorly on the left side the condition was most evident along the inner margin of the scapula and below it, whilst beyond the midaxillary line, passing forward, pigmentation seemed to have cleared towards the middle line of the body. On the right side the condition was not so marked along the inner border of the scapula, but about as well marked below it as on the left; in the mid and anterior axillary lines, and towards the middle line of the body, however, it was well in evidence.

It is interesting that in so marked a case the sides of the neck, usually the parts affected, should escape altogether. It has been observed that syphilitic pigmentation usually, as in this case, clears away very slowly.

In fair Europeans, of the same type as the patient, exposure to the sun in some parts of the world, and especially accidental exposure of a portion of the skin usually protected, may produce a pigmentation as definite and as deep in colour as the syphilitic described above. Such pigmentation is frequently, but not always, preceded by an inflammatory erythems; it is very permanent, like the syphilitic, and may take eighteen months to two jears to disappear, although there be no subsequent exposure to the sun.

Again, it is remarkable to what an extent scars and the cuticle round them tend to become pigmented in some moderately dark-skinned races, as, fur instance, the Chinese; and also how very permanent is such palbological cnloration, whether on an expose $d$ or unexposed part of the body. Obviously, then, permanency is not reculiar to ssphilitic pigmentation. 